\title{
EFEITOS SUCESSÓRIOS DA MULTIPARENTALIDADE
}

\section{ARTIGO ORIGINAL}

TOLEDO, Maurício de ${ }^{1}$

TOLEDO, Maurício de. Efeitos sucessórios da multiparentalidade. Revista Científica Multidisciplinar Núcleo do Conhecimento. Ano 05, Ed. 12, Vol. 09, pp. 118138. Dezembro de 2020. ISSN: 2448-0959, Link de acesso: https://www.nucleodoconhecimento.com.br/lei/efeitos-sucessorios

\section{RESUMO}

O propósito do presente artigo é o de analisar de forma crítica a decisão do Supremo Tribunal Federal que reconheceu a possibilidade da coexistência das filiações biológica e socioafetiva, chamada de multiparentalidade ou pluriparentalidade. Além disso, examina-se o provimento do Conselho Nacional de Justiça que busca dar parcial efetividade à decisão no âmbito dos cartórios de registro civil. Busca-se, também, investigar os diversos efeitos sucessórios do reconhecimento de múltiplos vínculos parentais, utilizando-se da legislação atual e trazendo o debate posto pela doutrina sobre as possíveis soluções para os conflitos gerados. Após ponderação de todo o conteúdo pesquisado, tenta-se viabilizar saídas justas e de acordo com os princípios que regem o ordenamento jurídico para as possibilidades abertas com relação aos diversos tipos de sucessão.

Palavras-chaves: Multiparentalidade, pluriparentalidade, sucessão, afetividade.

\section{INTRODUÇÃO}

Ao longo do tempo, diversas mudanças ocorrem na sociedade e no modo como as pessoas se relacionam. Neste contexto, as famílias passaram por diversas modificações, deixando de lado o caráter religioso para a valorizar o do afeto entre os

\footnotetext{
${ }^{1}$ Acadêmico de Direito.
} 
seus membros, além da redução do núcleo familiar. Aliado a isso, no campo jurídico, o Estado passou a intervir cada vez mais no seio familiar e a disciplinar de forma contundente essas relações.

Ressalta-se, aqui, a importância que a afetividade tem ganhado nas relações familiares, como se vê em diversas situações cotidianas que exigiram um regulamento específico, como a união estável entre pessoas do mesmo sexo. Em relação à parentalidade, vê-se que vínculos consanguíneos deixam de possuir uma condição preponderante para dividir o espaço com a filiação socioafetiva cada vez mais nas famílias atuais.

Assim, tendo em vista as novas estruturas familiares que se impõem, não é possível que o direito despreze essa realidade social vez que, conforme estatui o artigo 226 da Constituição Federal, a família é a base da sociedade e goza de proteção especial pelo Estado. Além disso, destaca-se que a dignidade da pessoa humana, fundamento da República Federativa do Brasil, exige que sejam dadas condições mínimas para que as pessoas possam viver de forma digna, incluindo-se a salvaguarda às suas relações.

No entanto, devido à enorme fluidez das relações humanas, pode ocorrer um certo distanciamento entre o ordenamento jurídico e o campo fático já que o legislador não consegue prever todas as situações possíveis, competindo, muitas vezes, ao Poder Judiciário analisar conflitos sem amparo legal expresso. Exemplo disso é a multiparentalidade, que apesar de ser uma realidade há tempos, ainda carece de disciplina normativa, mesmo que já incorporada ao direito de família.

A multiparentalidade, em si, nada mais é do que o reflexo da sociedade atual e de como as famílias têm se estruturado. A afetividade foi alçada à categoria de princípio fundamental. Com isso, inúmeros casos foram sendo judicializados e decisões divergentes foram causando uma enorme insegurança jurídica, levando o Supremo Tribunal Federal a apreciar a matéria e, de certa forma, pacificar o entendimento visando sua uniformização. 
Destarte, no primeiro capítulo deste trabalho, serão analisados a decisão proferida e os parâmetros definidos pela tese firmada, debatendo os principais pontos. Serão, também, considerados os princípios constitucionais aplicáveis ao direito de família e, de forma mais específica, à filiação, que ainda gera inúmeras discussões, pois é um vínculo irrevogável.

Além disso, o reconhecimento da multiparentalidade, além dos impactos diretos no direito de família, também gera consequências em outros campos do direito civil e das demais áreas do direito. Serão tratados, por fim, alguns efeitos sucessórios derivados do reconhecimento desse instituto.

A princípio, faz-se necessário o enfrentamento das sucessões dos descendentes, pois, o direito mais claro e um dos mais importantes decorrente da filiação é o do filho com relação à herança do ascendente. Logo, o segundo capítulo trará à discussão a sucessão dos descendentes à luz do que foi decidido pelo Supremo Tribunal Federal e os preceitos estabelecidos na Constituição Federal.

Em seguida, urge uma análise mais detalhada da via contrária da situação acima, logo, a sucessão dos ascendentes. Por conta disso, a terceira parte do trabalho se deterá às minúcias desta modalidade sucessória que ainda não foi frontalmente examinada em sede de repercussão geral, tampouco o Código Civil trata de forma cabal da matéria. Por fim, ainda na seara da sucessão dos ascendentes, será acrescentado ao debate a concorrência com eventual cônjuge ou companheiro.

O objetivo deste trabalho é demonstrar que todos os requisitos para recebimento da herança restam preenchidos em situações de multiparentalidade. Além disso, é premente a viabilização de discussões que busquem compreender situações ainda nebulosas na doutrina e na jurisprudência, pois é uma realidade cada dia mais recorrente. 


\section{RECONHECIMENTO DA MULTIPARENTALIDADE E A AFETIVIDADE COMO SEU FUNDAMENTO}

Antes de tratar diretamente da pluriparentalidade, requer-se um breve panorama da importância da afetividade no contexto das relações familiares, pois esta foi essencial para o reconhecimento daquela. Entretanto, de início, as relações familiares não eram pautadas por ela, mas por vínculos estritamente biológicos e, muitas vezes, precários e comparáveis à escravos.

Numa análise histórica, na gênese da sociedade ocidental, verifica-se que a família romana era, essencialmente, um agrupamento de pessoas subordinada a um chefe, a que se dava o nome de "gens". O chefe era uma figura patriarcal e exercia o domínio completo de todos os demais membros, havendo uma relação de completa subordinação dos membros à vontade do patriarca (PAES, 1971). Este modelo de organização vigorou incólume por séculos, passando por algumas modificações, porém a afetividade não possuía qualquer importância.

Em seguida, com o cristianismo ganhando um papel de predominância na cultura ocidental, a família passou a ter um caráter religioso de modo que o casamento era requisito de sua existência. Logo, apenas os frutos do matrimônio seriam legitimados e inseridos no âmbito familiar. Neste novo cenário, o caráter patriarcal não foi modificado, porém iniciou-se a imposição de direitos e deveres do pai para com os filhos, o que o proibia de vendê-los como escravos, por exemplo (DE CADEMARTORI, 2015).

Com o advento dos movimentos políticos e sociais a partir da Revolução Francesa e influenciados pela revolução industrial, o panorama começou a ser alterado. O ser humano passou a ser valorizado em seu caráter individual e subjetivo com a elevação dos ideais de liberdade, igualdade e fraternidade (CALFERÓN, 2017).

Consagra-se a isso a separação entre Estado e religião que passou a viger, oportunizando novas formas de se relacionar. Além disso, cabe ressaltar a importância da emancipação da mulher e seu ingresso no mercado de trabalho. 
Desta forma, a afetividade passou a ter cada vez mais espaço no âmbito familiar já que é uma característica inerente ao ser humano no mundo atual. A exteriorização disso se dá de forma tridimensional, conforme aduz Belmiro Pedro Marx Welter, tendo as esferas genética, afetiva e ontológica de manifestações (2012).

Essas dimensões do ser humano estão intrinsecamente conectadas e se comunicam. Logo, a afetividade resta caracterizada como base de todas as relações interpessoais e, no âmbito familiar, ganha um contorno ainda mais importante no que concerne à parentalidade.

Neste cenário, a Carta Magna rompeu com a família derivada unicamente do casamento, não tratando em rol taxativo os modelos familiares. Prova disso é o reconhecimento expresso da união estável ${ }^{[2]}$ e das famílias monoparentais ${ }^{[3]}$ como núcleos familiares. Assim, o parâmetro deixa de ser o vínculo sanguíneo para ser o afeto entre os membros.

De forma análoga, o Código Civi[l[ também inclui o parentesco advindo de outra forma que não o sanguíneo já que, na fluidez das relações atuais, diversas famílias são verdadeiros mosaicos plurais derivados de divórcios, separações e reconstituições (CHAVES, 2015). Por conta disso, a relação entre pais e filhos e padrastos e enteados são cada vez mais colocadas na mesma categoria, podendo prevalecer posteriormente ao rompimento da relação que a originou. O parentesco passa a ser uma construção e já não depende mais de possuir ou não vínculo biológico[5].

Ao julgar o Recurso Extraordinário 898.060 (BRASIL, 2016), afetado com repercussão geral, o Pleno do Supremo Tribunal Federal definiu tese no sentido de que é possível a coexistência da paternidade biológica e da socioafetiva, sendo de igual categoria e gozando dos mesmos direitos e deveres.

O caso fático tratado pelo STF, em apertado resumo, dizia respeito a uma ação de investigação de paternidade cumulada com pedido de prestação de alimentos, em que se constatou que a autora foi registrada pelo marido de sua mãe à época, mas que não era seu pai biológico, assemelhando-se à chamada "adoção à brasileira". Por toda 
sua vida, seu pai sempre a tratou como filha biológica, sendo revelada esta informação a ela apenas aos 18 anos.

Desta forma, o vínculo formado entre a autora e seu pai socioafetivo era, na realidade, muito mais forte e duradouro que eventual relação com o pai biológico. O julgamento, então, concentrou-se nas seguintes questões: seria possível a coexistência de mais de um vínculo parental ou deveria prevalecer apenas um? E, neste caso, qual deveria prevalecer?

Diversos argumentos foram trazidos à discussão, inclusive pelo Instituto Brasileiro de Direito de Família (IBDFAM), como amicus curiae que asseverou em sessão de julgamento ${ }^{[6]}$ a impossibilidade de afastar um vínculo afetivo construído por anos apenas pela descoberta da descendência genética. Em seu voto, o ministro relator Luiz Fux fundamentou seus argumentos de forma sólida no princípio da dignidade da pessoa humana. No entanto, nas palavras do ministro, este seria um "sobreprincípio" do qual deriva a busca da felicidade.

Sendo assim, a garantia a uma vida digna não se restringe aos meios básicos de sobrevivência, mas abrange também a possibilidade a uma vida feliz. Logo, o indivíduo deve ter assegurada sua autodeterminação pelo Estado que, além de promover mecanismos para tanto, não pode se imiscuir de reconhecer situações cotidianas ainda não abarcadas expressamente pelo ordenamento jurídico.

Além disso, o texto constitucional[7] impõe uma paternidade responsável, também decorrente da dignidade da pessoa humana, que acolhe o vínculo socioafetivo e o coloca no mesmo patamar do vínculo genético. Dessa maneira, não caberia ao legislador diferenciar uma parentalidade da outra, o que acaba por exigir como única solução o reconhecimento da pluriparentalidade.

No julgamento, o Ministro Dias Toffoli também ressaltou a importância do direito ao amor do pai biológico para com o filho, ainda que não o tenha criado, tendo em vista a necessidade de prover os cuidados básicos. Nesse mesmo sentido, a Ministra Carmen Lúcia citou que "amor não se impõe, mas cuidado sim, e esse cuidado me 
parece ser do quadro de direitos que são assegurados, especialmente no caso de paternidade e maternidade responsável".

Por fim, o STF reconheceu a existência da multiparentalidade e lhe deu sustentáculo fixando a seguinte tese: "A paternidade socioafetiva, declarada ou não em registro público, não impede o reconhecimento do vínculo de filiação concomitante baseado na origem biológica, com os efeitos jurídicos próprios."

Ressalte-se que, por mais que a tese firmada use a palavra "paternidade", tal entendimento é plenamente cabível para maternidades simultâneas (CALDERÓN, 2017). Além disso, o reconhecimento da multiparentalidade não se restringe, única e exclusivamente à filiação, gera um grande espectro de efeitos jurídicos, sendo alguns debatidos nos capítulos seguintes deste trabalho.

No entanto, é possível traçar de forma geral as principais decorrências da tese fixada pelo STF, tais como: a afetividade como categoria jurídica; a equiparação dos vínculos afetivos e biológicos; e o princípio da parentalidade responsável (CALDERÓN, 2017). Ademais, também é possível citar reflexos quanto à guarda, alimentos e alteração do nome, debatido de forma minuciosa no Provimento n. 63/2017 do Conselho Nacional de Justiça (CNJ, 2017), a seguir abordado.

Visando dar maior efetividade e agilidade ao reconhecimento da parentalidade socioafetiva, o Conselho Nacional de Justiça editou o Provimento n. 63/2017 para permitir a alteração do assento de nascimento de forma extrajudicial, perante o oficial de registro civil de pessoas naturais ${ }^{[8]}$, a fim de que conste no campo "filiação" o genitor socioafetivo. Desta forma, o procedimento estabelecido é mais célere e acessível do que um processo judicial que leva tempo e exige inúmeras formalidades, o que acabaria por inviabilizar o reconhecimento de uma situação tão recorrente na sociedade.

Nesse sentido, o ato normativo estabelece algumas regras para que a alteração do assento seja realizado, tais como: o pretenso genitor deve ser maior de 18 anos $^{[9]} \mathrm{e}$ com uma diferença mínima de 16 anos ${ }^{[10]}$ para o filho; é necessário haver a anuência 
dos pais registrais ${ }^{[11]}$; não podem reconhecer a parentalidade socioafetiva os irmãos entre si nem os ascendentes ${ }^{[12]}$; e, se maior de 12 anos, dependerá do consentimento do filho[ ${ }^{[13]}$.

Estas exigências assemelham-se muito às estabelecidas no Estatuto da Criança e do Adolescente quanto à colocação em família substituta e em relação à adoção. Percebe-se aqui que o $\mathrm{CNJ}$, ao editar o ato normativo, inovou ao dar celeridade ao procedimento, mas, ao mesmo tempo, impôs formalidades próprias da adoção à uma situação diferente. Desta forma, cabe uma crítica a este enrijecimento já que a parentalidade socioafetiva, por natureza, é uma situação fática e espontânea derivada do afeto e não destitui os pais biológicos de seu poder familiar, contrariamente ao que ocorre na adoção (BARANSKI, 2018).

Além disso, o provimento impõe outra limitação ao estabelecer que somente poderão ser acrescentados ao assento de nascimento a menção a mais um pai e uma mãe, além dos dois registrais ${ }^{[14]}$. Logo, vislumbra-se nessa disposição uma certa falta de razoabilidade, pois não há na decisão do STF qualquer barreira quanto à quantidade de concomitância de vínculos parentais socioafetivas, o que é pouco coerente tendo em vista a dinâmica das relações familiares. Ademais, considerando o princípio constitucional da legalidade ${ }^{[15]}$, não caberia a um ato infralegal estipular uma proibição que não consta expressamente em lei.

No entanto, a tese estabelecida pelo tribunal constitucional falhou ao não determinar quais seriam as diretrizes a serem seguidas em diversas circunstâncias advindas do reconhecimento da pluriparentalidade, sendo possível que novos questionamentos cheguem à corte. Nos próximos capítulos serão discutidos alguns destes efeitos e as possíveis formas de solução dentro do ordenamento jurídico pátrio atual.

\section{EFEITOS SUCESSÓRIOS NA LINHA DESCENDENTE}

Assim como proposto no início deste trabalho, serão trazidos ao debate alguns efeitos do reconhecimento da multiparentalidade, mais especificamente quanto ao direito sucessório. Primeiramente, serão verificadas as consequências jurídicas na sucessão 
dos descendentes em situações em que houver vínculos biológicos e socioafetivos simultaneamente.

A inovação trazida pelo julgamento do STF só foi possível pela evolução do direito brasileiro em diversos outros temas que tratam da família e de suas relações. Embora algumas dessas mudanças tenham demorado a se concretizar, como é o caso das uniões homoafetivas, não é possível retirar a importância delas e demonstrar que derivaram de diversas conquistas anteriores para se concretizarem.

No caso dos filhos, houve uma enorme transformação em seu tratamento jurídico no último século. O Código Civil de 1916 refletia de forma inequívoca o pensamento do início do século $\mathrm{XX}$, tendo caráter extremamente patriarcal e patrimonialista, o que refletia em diversas disposições em seu texto, como é o caso da abominável discriminação dos filhos em legítimos, ilegítimos, legitimados e adotivos (CALDERÓN, 2017).

À família era conferida uma proteção de instituição já que, essencialmente, possuía importância econômica ao ser caracterizada como uma unidade produtiva (LÔBO, 2019). Nesta realidade não havia espaço para a afetividade, tampouco para sua valorização.

Entretanto, com a emancipação econômica de seus membros, pela luta dos movimentos feministas e por meio da influência do pensamento psicanalítico (PEREIRA, 2020), este panorama foi sendo alterado a partir da segunda metade do século passado, sendo extirpada do ordenamento jurídico toda e qualquer diferenciação entre filhos pela Carta de $1988^{[16]}$.

Nesse sentido, aduz Rodrigo da Cunha Pereira: "Filhos ilegítimos, espúrios, bastardos, naturais e adulterinos, e outras designações discriminatórias, são proibidas pela Constituição da República. Filho é filho independentemente de sua origem. Não há filhos ilegítimos. Todos são legítimos." (PEREIRA, 2020)

Sendo assim, o princípio da igualdade da filiação passou a ser a regra e a isonomia entre os filhos deve ser assegurada em todas demais normas do sistema. O Código 
Civil de $2002^{[17]}$ acabou por confirmar e repetir as disposições constitucionais e estabelece que aos filhos de qualquer origem são garantidos os mesmos direitos e obrigações, em que pese ainda existir um grande preconceito social latente (MADALENO, 2019).

Com a abertura da sucessão, a herança transmite-se de forma imediata a todos os herdeiros do falecido ${ }^{[18]}$, em respeito ao princípio da saisine. De forma inicial, sempre se verifica a existência de disposição de última vontade válida e eficaz deixada pelo falecido e, não havendo, ou sendo esta parcial, deferir-se-á a sucessão aos herdeiros legítimos, obedecendo a ordem de vocação do artigo 1.829 e seguintes do Código Civil.

Ao tratar-se de sucessão envolvendo filhos socioafetivos, após a decisão paradigmática do Supremo Tribunal Federal, não restam dúvidas da qualidade de herdeiro deste em relação ao genitor socioafetivo. Alia-se a isso a isonomia entre os filhos imposta pela Constituição Federal, não cabendo qualquer distinção na divisão da herança. O vínculo gerado pelo afeto, então, é equiparado à filiação biológica e todos os filhos do falecido herdarão da mesma forma (SCOTT JUNIOR, 2011).

Em consequência disso, questionou-se, após a sedimentação da multiparentalidade pelo STF, se haveria limites do direito de herdar do filho socioafetivo, já que este poderia ser chamado à sucessão de um ascendente mais de duas vezes, como é o comum. Ao ser instado a se manifestar sobre o tema, o Superior Tribunal de Justiça posicionou-se, de forma acertada, no sentido de que os direitos hereditários advindos da parentalidade socioafetiva coexistem com aqueles decorrentes da filiação biológica (BRASIL, 2017).

Nesse sentido, foi aprovado o enunciado 632 na VIII Jornada de Direito Civil do STJ/CJF, em seu art. 1.596 que "nos casos de reconhecimento de multiparentalidade paterna ou materna, o filho terá direito à participação na herança de todos os ascendentes reconhecidos.". Portanto, em resumo, independentemente da quantidade de vínculos parentais que alguém possuir, seus direitos hereditários serão 
assegurados nas sucessões de todos seus ascendentes e em igualdade de condições com os demais herdeiros.

Outro aspecto relevante proveniente da tese firmada foi a suspeita, fundada, de gerar ações pleiteando o reconhecimento da parentalidade biológica apenas para figurar entre os herdeiros de eventual fortuna, as denominadas "demandas mercenárias" (SCHREIBER, 2016). Quanto a essa temática ainda há divergência doutrinária e jurisprudencial que exigirá intenso debate e maturação para que o entendimento seja pacificado.

De um lado do debate, argumenta-se que não deve ser reconhecida a filiação biológica quando o objetivo seja exclusivamente patrimonial. Nestes casos, seria possível apenas a declaração de descendência genética sem qualquer vínculo parental do qual emane direitos e deveres típicos da filiação (MADALENO, 1999).

Logo, nenhum direito hereditário seria concedido a quem tivesse, apenas e tão somente, esta intenção espúria. Agrava-se ainda mais a situação de filho que requer reconhecimento de vínculo biológico somente após o falecimento do genitor, o que fornece substrato a esta posição.

Tal doutrina ainda finca suas raízes no princípio da vedação ao enriquecimento ilícito ou sem causa, sustentando que a mera vinculação genética não gera, por si só, direito a suceder. Nessa seara, verificando-se eventual descumprimento de deveres parentais, a via adequada para solução do conflito caberia a uma ação de reparação de danos, associada à responsabilidade civil, e não a uma participação na herança como forma de compensação.

No entanto, este entendimento é anterior à decisão paradigmática do STF e parece não guardar relação com ela já que a tese firmada equipara ambas as formas de parentalidade e não cria qualquer tipo de hierarquia entre elas.

Por outro lado, de forma mais harmônica com a disciplina constitucional, observa-se a tese de que o mero receio de demandas fundadas em interesses escusos não deve obstaculizar o reconhecimento da multiparentalidade com todos seus efeitos próprios 
(SCHREIBER; LUSTOSA, 2017). Parte-se, aqui, do princípio da boa-fé objetiva verificada na conduta das partes e, havendo comportamento contrário na análise da situação fática, tal prática deve ser combatida e coibida.

Outrossim, o regramento constitucional erigiu o direito à herança ao status de direito fundamental que, como tal, deve ser tutelado pelo Estado. No ensinamento de Luiz Paulo Vieira de Carvalho (2019):

Além disso, é de recordar que o Direito à Herança é cláusula pétrea (art. $5^{\circ}, \mathrm{XXX)}$ e, em tais termos civis constitucionais, uma vez reconhecida e oposta ao termo de nascimento a multiparentalidade (a desaguar na presunção de veracidade do aludido registro), o recolhimento múltiplo de direito sucessório paterno ou materno nada mais é do que efeito natural e consequente da morte de quaisquer dos ascendentes a favor do descendente de primeiro grau (art. 1.829, I, do CC, c/c o art. 227, § 6º, da CRFB).

Logo, a regra é o reconhecimento e as exceções devem ser minuciosamente apreciadas no bojo do caso concreto. Exemplo disso seria o decurso do tempo entre o descobrimento do vínculo biológico pelo filho e a propositura da ação pertinente, sendo que, neste período, nenhuma conduta de aproximação ou requerimento de cumprimento de deveres parentais tenha sido praticada.

Ademais, seria pouco coerente carregar apenas o instituto da multiparentalidade com uma carga negativa e meramente patrimonial já que inúmeras ações dentro do direito de família (e no direito em geral) podem ter essa intenção. No entanto, como em qualquer outra situação, caberá ao operador do direito submeter o caso a uma profunda verificação de comportamento contraditório e abuso de direito já que não há direito absoluto.

\section{UMA VIA DE MÃO-DUPLA}

A relação que une os filhos a seus pais é denominada filiação, como já visto anteriormente. Do ponto de vista dos ascendentes essa ligação é caracterizada como parentalidade, desdobrando-se em paternidade, para o pai, e maternidade, para a 
mãe. Nas palavras de Gilda Ferrando, a "filiação instaura uma relação entre genitores e filhos que tem o mesmo conteúdo em termos de direitos e deveres recíprocos."[19]

Nesse sentido, a multiparentalidade assinala um conjunto de direitos e deveres que produzem efeitos tanto para o filho no que diz respeito aos pais, biológicos e socioafetivos, quanto dos pais para com os filhos. Portanto, ao ser reconhecido o vínculo parental, o ascendente também passa a ser detentor de uma série de direitos, inclusive hereditários, como será visto abaixo.

Ressalte-se que o entendimento a ser exposto retrata uma das consequências da multiparentalidade ainda não tratada de forma pormenorizada pelos tribunais. Logo, serão trazidos posicionamentos doutrinários possivelmente divergentes, já que a aplicação de um instituto sem amparo legal expresso exige uma ponderação de princípios e interpretação sistemática, visando, sempre, a busca de uma solução justa e razoável. Além disso, destaca-se que nas hipóteses colocadas sempre serão levadas em consideração a inexistência de disposição de última vontade válida e eficaz a fim de facilitar a compreensão.

Primeiramente, fazem-se necessários alguns apontamentos gerais acerca da sucessão legítima para fundamentar os argumentos posteriormente expostos. Desta forma, os ascendentes, assim como os descendentes e o cônjuge ou companheiro (em consonância à decisão paradigmática proferida pelo STF no tema de repercussão geral 498) (TARTUCE, 2020) são definidos no Código Civil como herdeiros necessários ${ }^{[20]}$. Sendo caracterizados como tais, sempre farão jus ao recebimento da legítima, constituída pela metade dos bens da herança ${ }^{[21]}$.

A condição de herdeiro necessário concedida a estas classes de sucessores provém da presunção de proximidade e afinidade que caracterizam a maior parte dessas relações. Nas palavras de Paulo Lôbo (2019):

A sucessão legítima necessária, também denominada sucessão legitima necessária, provém da concepção, primitiva e antiga, de ter o patrimônio de ficar, primacialmente, no círculo estreito da comunidade doméstica. Com o advento do Código Civil de 2002, passaram a ser considerados herdeiros necessários os descendentes, os ascendentes, o cônjuge 
sobrevivente ou o companheiro sobrevivente. Na legislação anterior, o cônjuge sobrevivente não se incluía entre os herdeiros necessários.

Sendo assim, tendo falecido uma pessoa sem deixar descendentes, sua sucessão será deferida aos ascendentes, em concorrência com o cônjuge ou convivente se houver ${ }^{[22]}$. Neste cenário, imagine-se o exemplo de alguém que faleceu antes de seus pais deixando um patrimônio de $R \$ 1.200 .000,00$ e sem ter contraído matrimônio ou ter mantido união estável. Sua herança, então, será dividida igualmente entre seus pais, cabendo $R \$ 600.000,00$ a cada um deles.

Até este ponto não se vislumbram grandes problemas a serem enfrentados, panorama alterado com a possibilidade da coexistência de múltiplos vínculos parentais. Cite-se, então o exemplo de uma pessoa que tenha deixado um pai e uma mãe biológicos e um pai socioafetivo. Nesta situação ainda não há entendimento pacificado, cabendo à doutrina e ao aplicador do direito a busca de uma solução viável tendo em vista a lacuna legislativa.

Sendo assim, duas correntes são postas para resolver este questionamento. A primeira baseia-se na aplicação do 1.836 do Código Civil[23] em que, primeiro dividese a herança em duas partes, sendo a linha materna e a linha paterna, e, em seguida, cada parte é fracionada pelo número de ascendentes daquela linha. Logo, no caso hipotético trazido, cada um dos pais receberia $R \$ 300.000 .00$, enquanto a mãe teria direito a $\mathrm{R} \$ 600.000,00$.

Este entendimento reconhece que a multiparentalidade ainda não foi expressamente tratada pela legislação brasileira, porém não desconsidera o regramento já existente que deve permanecer sendo aplicado. Tal argumento também está intimamente relacionado ao princípio constitucional da legalidade (CARVALHO, 2019).

De outro lado, situa-se a doutrina que defende a flexibilização das normas aplicáveis à sucessão por sua falta de preparo em relação à multiparentalidade (CASSETTARI, 2017). Por conta disso, a divisão igualitária da herança pela quantidade de ascendentes faz-se necessária e mais justa. Consubstanciando este raciocínio, foi aprovado o enunciado subsequente na VIII Jornada de Direito Civil: 
ENUNCIADO 642: Nas hipóteses de multiparentalidade, havendo o falecimento do descendente com o chamamento de seus ascendentes à sucessão legítima, se houver igualdade em grau e diversidade em linha entre os ascendentes convocados a herdar, a herança deverá ser dividida em tantas linhas quantos sejam os genitores.

Logo, utilizando-se dos princípios da razoabilidade e da proporcionalidade, a partilha do cenário fictício acima mencionado deveria se dar em três quotas iguais no valor de $\mathrm{R} \$ 400.000,00$. Num primeiro momento, parece ser esta a posição mais ponderada até que a atividade legislativa supra essa carência.

Visando a atualização do código civilista, Luiz Paulo Vieira de Carvalho (2019) propõe a seguinte redação para o artigo 1.836:

Art. 1.836. Na falta de descendentes, são chamados à sucessão os ascendentes, em concorrência com o cônjuge sobrevivente.

$\S 1^{\circ} \mathrm{Na}$ classe dos ascendentes, o grau mais próximo exclui o mais remoto, sem distinção de linhas.

$\S 2^{\circ}$ Havendo igualdade em grau e diversidade em linha, os ascendentes da linha paterna herdam a metade, cabendo a outra aos da linha materna.

Parágrafo único. Em caso de multiparentalidade, falecido o descendente sem deixar prole, o quinhão correspondente aos ascendentes, será dividido na mesma proporção do número de pais ou mães sobreviventes.

Embora sugestões como essa sejam de extrema importância para a evolução do ordenamento jurídico, sabe-se que a atividade legislativa se baseia em outras motivações, além da necessidade da regulação da vida social. Nesse ínterim, casos como este exigirão uma solução e 0 Estado-juiz, por força de comando constitucional[24], não poderá se esquivar ou aguardar os demais poderes atuarem para dar uma resposta ao jurisdicionado.

Outro ponto alvo de contenda é a situação dos avós, no entanto caberia perfeitamente a aplicação da proposição acima como será visto. Destaca-se de antemão que, contrariamente ao que ocorre na linha descendente, o direito de representação é expressamente vedado pelo Código Civil na linha ascendente ${ }^{[25]}$. 
Logo, falecendo alguém deixando apenas um pai e dois avós maternos, aquele herdará a totalidade da herança, chamando-se os ascendentes de $2^{\circ}$ grau à sucessão apenas na ausência de quaisquer pais ou mães. Sendo assim, em casos de multiparentalidade, uma pessoa poderá ter até oito avós (nos termos do Provimento n. 63/2017 do CNJ, já analisado acima) sendo que a divisão por linhas antes da divisão por cabeça implicaria em clara desigualdade.

Sugere-se, então, o seguinte exemplo em que o falecido possuísse dois pais e uma mãe, todos pré-mortos, e possuísse todos os avós vivos na abertura da sucessão. Caberia, pela primeira corrente, aos ascendentes de sua genitora metade da herança e a outra metade aos quatro avós paternos, o que geraria uma quota hereditária duas vezes maior que a outra.

Por conseguinte, a segunda concepção é a que mais apresenta razoabilidade ao distribuir o patrimônio do falecido a todos os ascendentes de mesmo grau de forma equânime, sem distinções de linhas, seguindo a proposta de alteração normativa supra. De outra feita, importa trazer aqui alguns pontos a respeito da fundamentação da tese acima apresentada.

De início, todo o ordenamento jurídico brasileiro, em especial a Carta Maior, exalta e erige o princípio da igualdade com um de seus pilares, muitas vezes expressos ${ }^{[26]}$, e por outras implícitos, como no caso da igualdade dos filhos citada em capítulo anterior. Ora, se a própria Constituição não diferencia os filhos com relação aos pais, não cabe qualquer entendimento que diferencie os pais relativamente à sua prole.

Além disso, é incumbência dos pais, sem distinção, o exercício do poder familiar de forma simultânea e em igualdade de condições, caracterizando-se como outro pressuposto da igualdade aqui clamada. Nesse diapasão, verifica-se que o Código Civil traça uma diferenciação um tanto arcaica em linhas paterna e materna, sustentando uma divisão da herança embasada no gênero dos ascendentes.

$\mathrm{Na}$ sociedade atual e com o advento de todas as conquistas objetivando a igualdade de gênero, além do reconhecimento jurídico das uniões homoafetivas, parece 
desarrazoada tal discriminação imposta à sucessão dos ascendentes. No entanto, ressalte-se que tal discussão só pôde ser iniciada a partir do reconhecimento da pluriparentalidade, sendo certo que o legislador não considerou essa realidade, e talvez nem poderia ter considerado, quando da elaboração do diploma legal.

Superada de forma minuciosa a contenda acerca da sucessão dos ascendentes, cumpre agora tratar da situação do cônjuge ou companheiro sobrevivente. Preliminarmente, imperioso delinear alguns aspectos atinentes ao tratamento jurídico direcionado ao cônjuge e convivente atualmente.

O Código Civil de 2002 inovou ao inserir o cônjuge no rol de herdeiros necessários, que era restrito aos descendentes e ascendentes no diploma civil anterior e que vigeu pelo século passado. Essa ausência dava-se pelo fato de que o regime comum anterior era o da comunhão universal de bens, no qual o cônjuge já possuía metade de todos os bens de seu consorte. No entanto, isso levava a algumas injustiças quando se tratava de outros regimes, tema não objeto deste trabalho.

Contudo, embora tenha sido uma grande evolução legislativa, ao companheiro foi dado um tratamento diferenciado e sem a relevância merecida no Código Civil[27]. Atento a essa realidade, o plenário do Supremo Tribunal Federal decidiu em sede de repercussão gera [ ${ }^{[28]}$ pela inconstitucionalidade do artigo 1.790 da norma supra, sendo aplicável ao companheiro o regramento do artigo 1.829. Logo, em questões sucessórias, resta evidente a equiparação do cônjuge supérstite ao convivente.

Em que pese o STF ter se imiscuído de enfrentar o tema de forma direta e afirmar que o companheiro deve, também, constar no rol de herdeiros necessários, a doutrina é ampla neste sentido, conforme pontua Flavio Tartuce (2020):

A minha posição doutrinária, que merece mais uma vez ser esclarecida, é que o companheiro deve ser equiparado ao cônjuge para todos os fins sucessórios, sendo reconhecido como herdeiro necessário e com tratamento unificado quanto ao direito real de habitação, tema ainda a ser exposto e desenvolvido. 
Neste cenário, o Código de $2002^{[29]}$ é expresso quanto a estes casos. tratando-se de concorrência entre ascendentes de primeiro grau e cônjuge ou companheiro, este herdará um terço da herança. Por outro lado, sendo os herdeiros da linha ascendente avós, ao cônjuge ou companheira é reservada a metade da herança.

Sendo assim, acrescente-se ao exemplo do item anterior (falecido com dois pais e uma mãe) a existência, também, de cônjuge sobrevivo. Nessa seara, independe o regime de bens em que celebrado o casamento[30]. Logo, seguindo o preceito do artigo 1.837 , aliado aos princípios da proporcionalidade e razoabilidade, aparenta ser mais correta a divisão em quatro quotas iguais para cada um dos sucessores.

No entanto, caso a sucessão envolva ascendentes em $2^{\circ}$ grau, ainda carece de investigação doutrinária a permanência ou não da reserva de metade da herança. Ao analisar o tema, a doutrina também se divide, porém é forte o entendimento que a divisão deverá sempre ser por cabeça, buscando-se a finalidade trazida pelo artigo 1.837 de igualar o cônjuge aos ascendentes, conforme assevera José Fernando Simão e Zeno Veloso (TARTUCE, 2020).

\section{CONSIDERAÇÕES FINAIS}

O Supremo Tribunal Federal, ao reconhecer a possibilidade da coexistência das paternidades biológica e afetiva, inovou o ordenamento pátrio. Além disso, a decisão busca corrigir uma injustiça e dar guarida a uma realidade social, que é a multiparentalidade. Com isso, a afetividade, que já era o fundamento fático das relações familiares, foi alçada à categoria de princípio.

A evolução jurisprudencial veio na esteira da ausência de atividade legiferante renovadora, problema crônico no Brasil. Desta forma, a família mosaico, tão comum na sociedade, passou a ter um tratamento digno por parte do Estado, ainda que por meio do Poder Judiciário.

No entanto, em que pese ser uma decisão paradigmática e histórica que fez valer direitos por tempos renegados, trouxe ao sistema jurídico uma figura aparentemente 
incompatível. Acrescente-se a isso a falha do STF em delimitar as inúmeras consequências advindas do instituto nas mais diversas áreas do direito.

Este trabalho estabeleceu um recorte para analisar os impactos da decisão no campo do Direito das Sucessões, buscando traçar o panorama que surgiu e seus possíveis desdobramentos. Para a sucessão dos descendentes, verificou-se que os conflitos inicialmente gerados não passaram de aparentes conflitos.

Logo, com a equiparação dos vínculos parentais, uma pessoa poderia vir a ser herdeira de mais de dois ascendentes, como é o comum. Tal situação não configura qualquer injustiça, já que a própria Constituição Federal estatui que não há diferença entre os filhos, portanto, não devendo haver qualquer distinção no âmbito sucessório.

Por outro lado, foi colocada à luz debate sequer enfrentado pelos ministros do STF, mas que, pelo teor da decisão, é um dos efeitos diretos. Nesse sentido, a sucessão dos ascendentes deve ser alvo de ampla discussão, já que as disposições do Código Civil pouco contribuem para a resolução do conflito.

Por conseguinte, se não existe (e não devem existir) diferença no tratamento dos filhos, não há que se falar em qualquer distinção quanto aos pais. Não há, então, motivos justos, em que pese entendimento contrário, para dividir a herança em linhas, sendo imperiosa a partilha pela quantidade de ascendentes aptos a suceder.

Com relação ao cônjuge e companheiro, cabe, também, uma interpretação teleológica do regramento civilista em que há uma clara finalidade de equiparar o cônjuge ao ascendente como herdeiros. Destaque-se, aqui, a controvérsia pendente sobre a reserva ou não da quota parte do cônjuge quando concorrer com os ascendentes de 2o grau.

Diante do exposto, conclui-se que o tema possui alto grau de relevância e, para que grande parte dos debates fosse pacificados ou, ao menos, estreitados, uma inovação legislativa é premente. Entretanto, enquanto tal aperfeiçoamento normativo não se concretiza, cabe ao operador do direito utilizar-se das demais ferramentas disponíveis para dar, ou tentar dar, uma resposta às demandas e, também, à sociedade. 


\section{REFERÊNCIAS}

AZEVEDO, Álvaro Villaça. Curso de direito civil, v. 7: direito das sucessões. São Paulo: Saraiva, 2018. Recurso online ISBN 9788553610365.

BARANSKI, Julia Almeida. Tribuna da Defensoria: A parentalidade socioafetiva no Provimento 63/2017 do CNJ, 2018. Disponível em: https://www.conjur.com.br/2018-jun-19/tribuna-defensoria-parentalidadesocioafetiva-provimento-632017-cnj. Acesso em: out. 2020.

BRASIL. Supremo Tribunal Federal. Recurso Extraordinário no 898.060 / SP. Recorrente: A.N. Recorrido: F.G. Relator: Min. Luiz Fux. Julgado em: 21 set. 2016. DJe: 292016.2 set. 29 Disponível http://www.stf.jus.br/arquivo/cms/noticiaNoticiaStf/anexo/RE898060.pdf. Acesso em: out. 2020.

. Superior Tribunal de Justiça. Recurso Especial no 1618230/RS 2016/0204124-4. Recorrente: V.L. Recorrido: R.M.L. Relator: Ministro Ricardo Villas Bôas Cueva. Julgado em: 28 mar. 2017. Terceira Turma, Data de Publicação: DJe 10/05/2017.

. Conselho Nacional de Justiça. Atos Administrativos. Provimento no 63 de 14/11/2017. Disponível em: https://atos.cnj.jus.br/atos/detalhar/2525. Acesso em: out. 2020

. Constituição (1988). Constituição da República Federativa do Brasil. Brasília.

. Lei oํ 10.406, de 10 de janeiro de 2002. Código Civil. Brasília.

CALDERÓN, Ricardo. Princípio da afetividade no direito de família, 2. Rio de Janeiro: Forense, 2017. Recurso online ISBN 9788530977153. 
CARVALHO, Luiz Paulo Vieira de. Direito das sucessões, 4. Rio de Janeiro: Atlas, 2019. Recurso online ISBN 9788597017328.

CASSETTARI, Christiano. Multiparentalidade e parentalidade socioafetiva: efeitos jurídicos, 3. Rio de Janeiro: Atlas, 2017. Recurso online ISBN 9788597010602.

CHAVES, Marianna. Famílias mosaico, socioafetividade, e multiparentalidade: breve ensaio sobre as relações parentais na pós-modernidade. Anais do IX Congresso Brasileiro de Direito de Família. IBDFAM: Belo Horizonte, 2015, p. 143158. Disponível em: https://www.ibdfam.org.br/assets/upload/anais/296.pdf_Acesso em: out. 2020

DE CADEMARTORI, Daniela Mesquita Leutchuk; PASIN, Elizabeth Regina Machado. A constitucionalização da família: o valor jurídico do afeto. Revista da Faculdade de Direito, v. 35, n. 2, p. 87-120, 2015. Disponível em: http://www.repositorio.ufc.br/bitstream/riufc/11753/1/2014_art_dmlcademartori.pdf. Acesso em: 27 out. 2020.

FERRANDO, Gilda. Manuale di diritto di famiglia. Roma-Bari: Laterza, 2005, p. 234.

GAGLIANPO, Pablo Stolze. Novo curso de direito civil, v. 7: direito das sucessões, 7. São Paulo: Saraiva, 2019. Recurso online ISBN 9788553617821.

LÔBO, Paulo. Direito civil, v. 5: famílias, 10. São Paulo: Saraiva, 2019. Recurso online ISBN 9788553616909.

. Direito civil, v. 6: sucessões, 6. São Paulo: Saraiva, 2019. Recurso online ISBN 9788553616763.

MADALENO, Rolf. Direito de Família: aspectos polêmicos, 2. ed. rev. e atual. Porto Alegre: Livraria do Advogado, 1999. 182 p.

Direito de família, 10. Rio de Janeiro: Forense. 2019. Recurso online ISBN 9788530987961. 
Sucessão legítima, 2. Rio de Janeiro: Forense, 2020. Recurso online ISBN 9788530990558.

MALUF, Adriana Caldas do Rego Freitas Dabus. Novas modalidades de família na pós-modernidade. São Paulo: Atlas, 2010. Recurso online ISBN 9788522472895.

NADER, Paulo. Curso de direito civil, v.6: direito das sucessões, 7. Rio de Janeiro: Forense, 2016. Recurso online ISBN 9788530968748.

NUNES, Rizzatto. Manual da monografia jurídica, 12. São Paulo: Saraiva, 2017. Recurso online ISBN 9788553600861.

PAES, Elpídio Ferreira. Estrutura e evolução da família romana. 1971. Disponível em: https://seer.ufrgs.br/revfacdir/article/view/67468/38521. Acesso em: 27 out. 2020

PEREIRA, Caio Mario da Silva. Instituições de direito civil, v. 6: direito das sucessões, 27. Rio de Janeiro: Forense, 2020. Recurso online (Clássicos Forense). ISBN 9788530990572.

PEREIRA, Rodrigo da Cunha. Direito das famílias. Rio de Janeiro: Forense, 2020. Recurso online ISBN 9788530990824.

RIZZARDO, Arnaldo. Direito das sucessões, 11. Rio de Janeiro: Forense, 2019. Recurso online ISBN 9788530984762.

Direito de família, 10. Rio de Janeiro: Forense, 2018. Recurso online ISBN 9788530983062.

SCALQUETTE, Ana Claudia Silva. Família \& sucessões, 8. São Paulo: Grupo Almedina, 2020. Recurso online ISBN 9786556270210.

SCHREIBER, Anderson. STF, Repercussão Geral 622: a Multiparentalidade e seus Efeitos. Carta Forense. Publicado em, v. 26, 2016. Disponível em: http://www.cartaforense.com.br/conteudo/artigos/stf-repercussao-geral-622-amultiparentalidade-e-seus-efeitos/16982. Acesso em: out. 2020. 
SCHREIBER, Anderson; LUSTOSA, Paulo Franco. Efeitos jurídicos da multiparentalidade. Pensar-Revista de Ciências Jurídicas, v. 21, n. 3, p. 847-873, 2017. Disponível em: https://periodicos.unifor.br/rpen/article/view/5824/pdf. Acesso em: out. 2020.

SCOTT JUNIOR, Valmôr. Efeitos sucessórios da paternidade socioafetiva. Revista Sociais e Humanas, [S.I.], v. 23, n. 2, p. 35-46, jun. 2011. ISSN 2317-1758. Disponível em: https://periodicos.ufsm.br/sociaisehumanas/article/view/3203/1754. Acesso em: out. 2020.

TARTUCE, Flávio. Direito civil, v. 6: direito das sucessões, 13. Rio de Janeiro: Forense, 2020. Recurso online ISBN 9788530989408.

. Direito civil, v. 5: direito de família, 15. Rio de Janeiro: Forense, 2020. Recurso online ISBN 9788530989385.

TEPEDINO, Gustavo. Fundamentos do direito civil, v. 7: direito das sucessões. Rio de Janeiro: Forense, 2020. Recurso online ISBN 9788530989903.

VENOSA, Sílvio de Salvo. Direito civil, v. 5: família e sucessões, 20. Rio de Janeiro: Atlas, 2020. Recurso online ISBN 9788597024777.

WELTER, Belmiro Pedro Marx. Teoria Tridimensional do Direito de Família. Revista do Ministério Público do Rio Grande do Sul. Porto Alegre. n. 71, jan. 2012 abr. 2012, p. 127-148. Disponível em: http://www.amprs.org.br/arquivos/revista_artigo/arquivo_1342124687.pdf. Acesso em: out. 2020.

\section{APÊNDICE - REFERÊNCIAS DE NOTA DE RODAPÉ}

2. Art. 226. A família, base da sociedade, tem especial proteção do Estado. 
$\S$ 3ํ Para efeito da proteção do Estado, é reconhecida a união estável entre o homem e a mulher como entidade familiar, devendo a lei facilitar sua conversão em casamento.

3. Art. $226 \S 4^{\circ}$ Entende-se, também, como entidade familiar a comunidade formada por qualquer dos pais e seus descendentes.

4. Art. 1.593 - O parentesco é natural ou civil, conforme resulte de consanguinidade ou outra origem.

5. Idem

6. Disponível em: https://www.youtube.com/watch?v=qYDKX859BnA

7. Art. $226 \S 7^{0}$ Fundado nos princípios da dignidade da pessoa humana e da paternidade responsável, o planejamento familiar é livre decisão do casal, competindo ao Estado propiciar recursos educacionais e científicos para o exercício desse direito, vedada qualquer forma coercitiva por parte de instituições oficiais ou privadas.

8. Art. 10. O reconhecimento voluntário da paternidade ou da maternidade socioafetiva de pessoa de qualquer idade será autorizado perante os oficiais de registro civil das pessoas naturais.

9. Art. 10. $\S 2^{\circ}$ Poderão requerer o reconhecimento da paternidade ou maternidade socioafetiva de filho os maiores de dezoito anos de idade, independentemente do estado civil.

10. Art. 10. $\S 4^{\circ} \mathrm{O}$ pretenso pai ou mãe será pelo menos dezesseis anos mais velho que o filho a ser reconhecido.

11. Art. 11. $\S 5^{\circ} A$ coleta da anuência tanto do pai quanto da mãe e do filho maior de doze anos deverá ser feita pessoalmente perante o oficial de registro civil das pessoas naturais ou escrevente autorizado. 
12. Art. 10. $\S 3^{\circ}$ Não poderão reconhecer a paternidade ou maternidade socioafetiva os irmãos entre si nem os ascendentes.

13. Art. 11. $\S 4^{\circ}$ Se o filho for maior de doze anos, o reconhecimento da paternidade ou maternidade socioafetiva exigirá seu consentimento.

14. Art. 14. O reconhecimento da paternidade ou maternidade socioafetiva somente poderá ser realizado de forma unilateral e não implicará o registro de mais de dois pais ou de duas mães no campo FILIAÇÃO no assento de nascimento.

15. Art. 5․ II - ninguém será obrigado a fazer ou deixar de fazer alguma coisa senão em virtude de lei

16. Art. 227. $\S 6^{\circ}$ Os filhos, havidos ou não da relação do casamento, ou por adoção, terão os mesmos direitos e qualificações, proibidas quaisquer designações discriminatórias relativas à filiação.

17. Art. 1.596. Os filhos, havidos ou não da relação de casamento, ou por adoção, terão os mesmos direitos e qualificações, proibidas quaisquer designações discriminatórias relativas à filiação.

18. Art. 1.784. Aberta a sucessão, a herança transmite-se, desde logo, aos herdeiros legítimos e testamentários.

19. Tradução livre do texto: "la filiazione instaura un rapporto tra genitori e figli che ha lo stesso contenuto in termini di diritti e doveri reciprocl" (Manuale di diritto di famiglia. Roma-Bari: Laterza, 2005, p. 234).

20. Art. 1.845. São herdeiros necessários os descendentes, os ascendentes e o cônjuge.

21. Art. 1.846. Pertence aos herdeiros necessários, de pleno direito, a metade dos bens da herança, constituindo a legítima.

22. Art. 1.829. A sucessão legítima defere-se na ordem seguinte: 
II - aos ascendentes, em concorrência com o cônjuge;

Art. 1.836. Na falta de descendentes, são chamados à sucessão os ascendentes, em concorrência com o cônjuge sobrevivente.

23. Art. 1.836. Na falta de descendentes, são chamados à sucessão os ascendentes, em concorrência com o cônjuge sobrevivente.

$\S 1^{\circ} \mathrm{Na}$ classe dos ascendentes, o grau mais próximo exclui o mais remoto, sem distinção de linhas.

$\S 2^{\circ}$ Havendo igualdade em grau e diversidade em linha, os ascendentes da linha paterna herdam a metade, cabendo a outra aos da linha materna.

24. Art. 5 XXXV - a lei não excluirá da apreciação do Poder Judiciário lesão ou ameaça a direito

25. Art. 1.852. O direito de representação dá-se na linha reta descendente, mas nunca na ascendente.

26. Art. 5o Todos são iguais perante a lei, sem distinção de qualquer natureza, garantindo-se aos brasileiros e aos estrangeiros residentes no País a inviolabilidade do direito à vida, à liberdade, à igualdade, à segurança e à propriedade, nos termos seguintes:

I - homens e mulheres são iguais em direitos e obrigações, nos termos desta Constituição

27. Art. 1.790. A companheira ou o companheiro participará da sucessão do outro, quanto aos bens adquiridos onerosamente na vigência da união estável, nas condições seguintes:

I - se concorrer com filhos comuns, terá direito a uma quota equivalente à que por lei for atribuída ao filho; 
II - se concorrer com descendentes só do autor da herança, tocar-Ihe-á a metade do que couber a cada um daqueles;

III - se concorrer com outros parentes sucessíveis, terá direito a um terço da herança; IV - não havendo parentes sucessíveis, terá direito à totalidade da herança.

28. Informativo n. 864 do Supremo Tribunal Federal. Disponível em: http://stf.jus.br/arquivo/informativo/documento/informativo864.htm\#Sucess\%C3\%A3o \%20e\%20regime\%20diferenciado\%20para\%20c\%C3\%B4njuges\%20e\%20companh eiros. Acesso em: out. 2020

29. Art. 1.837. Concorrendo com ascendente em primeiro grau, ao cônjuge tocará um terço da herança; caber-Ihe-á a metade desta se houver um só ascendente, ou se maior for aquele grau.

30. Art. 1.829. A sucessão legítima defere-se na ordem seguinte:

II - aos ascendentes, em concorrência com o cônjuge.

Enviado: Dezembro, 2020.

Aprovado: Dezembro, 2020. 